\title{
ANALISIS KESULITAN SISWA SMP DALAM MENYATAKAN PERISTIWA SEHARI-HARI DAN MENURUNKAN RUMUS LUAS BANGUN DATAR SEGIEMPAT
}

\author{
${ }^{1}$ Merlin Uru Endu, ${ }^{2}$ Maria Goreti Nina \\ IKIP Siliwangi Bandung \\ 1'merlinuru@gmail.com,2mariagoretynina@gmail.com
}

\begin{abstract}
The purpose of this study was to find out how the mathematical communication skills of students in solving the problem of flat building of class VII triangles in one of the SMP in the city of Cimahi. Data collection uses written tests for 33 students. The research method used is descriptive qualitative research that is analyzing students' difficulties in solving mathematical communication skills on indicators stating everyday events and lowering the quadrangular flat building area formula of grade VII students of junior high school. The results of this study can be concluded that there are $6.06 \%$ ( 2 students) who have excellent mathematical communication skills, 93.94\% (33 students) have good mathematical communication skills and $0 \%$ (no students) who have communication skills mathematically is not good at problem 1 which indicator states everyday events and decreases the formula of quadrilateral flat building. This is due to the lack of ability of students to communicate their ideas so that they cannot solve problems in the given questions and even if asked they can only smile and be quiet.
\end{abstract}

Keywords: The difficulties of students, The quadrangular flat building formula

\begin{abstract}
Abstrak
Tujuan penelitian ini untuk mendeskripsikan jenis-jenis kesalahan siswa dalam menyelesaikan soal tentang materi bangun datar segiempat kelas VII di salah satu SMPN di kota Cimahi. Pengambilan data menggunakan tes tulis kepada 33 orang siswa. Metode penelitian yang digunakan adalah penelitian deskriptif kualitatif yang bersifat menganalisis kesulitan siswa dalam menyelesaikan soal kemampuan komunikasi matematis pada indikator menyatakan peristiwa sehari-hari dan menurunkan rumus luas bangun datar segiempat siswa kelas VII SMP. Hasil penelitian yang dapat disimpulkan adalah terdapat $6,06 \%$ (2 siswa) yang memiliki kemampuan komunikasi matematis yang sangat baik, 93,94\% (33 siswa) memiliki kemampuan komunikasi matematis cukup baik dan 0\%(tidak ada siswa) yang memiliki kemampuan komunikasi matematis kurang baik pada soal 1 yang indikator menyatakan peristiwa seharihari dan menurunkan rumus luas bangun datar segiempat. Ini disebabkan karena kurang mampunya siswa untuk mengkomunikasikan ide-ide yang mereka miliki sehingga membuat mereka tidak dapat memecahkan masalah dalam soal yang diberikan dan bahkan kalau ditanyakan hanya bisa tersenyum dan diam.
\end{abstract}

Kata Kunci: Kesulitan siswa, Rumus luas bangun datar

How to cite: Endu, M. U., Nina, M. G. (2019). Analisis Kesulitan Siswa SMP dalam Menyatakan Peristiwa Sehari-hari dan Menurunkan Rumus Luas Bangun Datar Segiempat. JPMI - Jurnal Pembelajaran Matematika Inovatif, 2 (1), 51-56.

\section{PENDAHULUAN}

NCTM (Junaidah, 2013:54) menyatakan salah satu kemampuan komunikasi penting yang harus ditingakatkan dalam proses pembelajaran matematika adalah kemampuan komunikasi". Depdiknas (Danaryanti \& Noviani, 015:204) menyatakan, "kemampuan komunikasi merupakan salah satau kemampuan yang dituntut dalam kurikulum tingkat stuan pendidikan 
(KTSP)". Sehingga proses pembelajaran matematika sangat diperlukan kemampuan komunikasi matematis, karena didalam mengkomunikasikan matematis siswa mampu mengeluarkan ide-ide matematik secara lisan, ataupun tulisan. Siswa yang mampu berkomunikasi dengan lebih mudah untuk menyelesaikan permasalahan yang ditemukan pada matematika.

Hal tersebut sejalan dengan pernyataan, Rosyana, (Hartono, 2015) "kemampuan komunikasi harus dimiliki siswa dapat memahami permasalah matematika yang dierikan dan mengutrakan ide-ide penyelesain dari permasalahan tersebut, serta memberika argumen atas ide yang diutarakannya". Demikian juga Presensi dan Bassett (Hartono, 2015: 274) menyatakan, "tampa komunikasi dalam melakukan proses dalam aplikasi matematika".

Untuk mengatasi masalah tersebut diperlukan suatu rancangan pembelajaran yang dapat mendorong meningkatnya kemampuan komunikasi matematika siswa.Kemapuan komunikasi matematika bergantung pada kemampuan mengumpulkan, mengorganisir, dan menjelaskan pemikiran, menemukan apa yang diketahui dan apa yang tidak diketahui, dan berpikir jernih (thinkingclearly). Adapun bentuk kemampuankemampuan komunikasi dalam matemat ika menurut rekomendasi NCTM mencakup aspek-aspek representasi dan wacana (representing discourse), membaca (reading), menulis (writing), dan diskusi dan evaluasi (discussion and evaluating)

Tetapi kenyataanya siswa mengalami kesulitan dalam mengkomunikasikan matematika dalam dunianyata. Bahkan kebanyakan siswa yang cerdas dalam matematika sering kurang mengkomunikasikan ide dengan baik atau menyampaikan pemikiranya. Jika hal ini terus dibiarkan hal ini membuat siswa kurang mampu berkomunikasi menggunakan matematika.

Untuk itu perlu dilakukan inovasi pembelajaran yang dirancang agar siswa terbias mengkontruksi pengetahuannya dan menumbuh kembangkan kemampuan komunikasi matematis. Adapun Indikator kemammpuan komunikasi matematis yang dibahasa yaitu kesulitan siswa menyelesaiakan soal tentang materi bangun datar segiempat. Indikator yang digunaka adalah salah satu soal dari hasil uji instrumen; yaitu bangun datar segitiga dan segiempat. pada materi yang dibeikan ini berkaitan nyata dalam kehidupan sehari-hari agar siswa mampu mengkomunikasikannya, namun banyak siswa yang kemampuan komunikasi matematikanya belum baik. Dengan menggunakan soal cerita memungkinkan siswa dapat berkomunikasi dengan baik.

Menurut (Haji, 2012:4) menyatakan Soal cerita merupakan modifikasi dari soal-soal hitung yang berkaitan dengan dunianyata siswa. penyajian soal dalam bentuk cerita merupakan usaha menciptakan suatu ceita untuk menrapakan konsep atau materi sesuai dengan pengalaman sehari-hari.

\section{METODE}

Jenis penelitian merupakan penelitian deskriptif menganalisis pada indikator kesulitan siswa SMP menyelesaiakn soal cerita materi bangun datara segiempat salah satu SMPN di kota Cimahi. Peneliti diberikesempatan untuk penelitian di sekolah tersebut, dipilih kelas VIIF. Metode pengumpulan sampel meliputi: Tes tulis untuk mengukur keterampilan siswa dalam soal cerita. Dalam penelitian ini, akan dibahas tentang bagaimana tingkat kesulitan matematis siswa pada mater ibangun datar segitiga-segiempat.

\section{HASIL}




\section{Hasil}

Penelitian ini dilaksanakan pada salah satu SMP Negeri kota Cimahi. Adapun bentuk soal instrumen penelitian yang digunaka.

Tabel 1.1 Instrumen Penelitian

Soal
Pak Danang mempunyai sawah yang
berbentuk persegi panjang jika keliling
sawah tersebut 52m, bagaimana cara
mengetahui luas sawah tersebut jika
diketahui panjan g delapan $\boldsymbol{x}$ meter dan
lebarnya $\boldsymbol{x}$ ditamabah delapan meter

Jawaban

Diket: $\mathrm{P}=8 x \mathrm{~m}$

$\mathrm{L}=x+8 m$

$\mathrm{K}=52 \mathrm{~m}$

Ditanya : Luas sawah Pak Danang,

maka terlebidahulu menentukan

panjang dan lebarnya dengan

menggunakan rumus keliling persegi

panjang seperti berikut:

$\mathrm{K}=2 \mathrm{P}+21$

$52=2(8 x)+2(x+8)$

$52=16 x+2 x+16$

$36=18 x$

$2=x$

Sehingga dapat diketahui panjang $8(2) m=16 m$ dan lebarnya $(2+8)=$ $10 \mathrm{~m}$

Maka luas sawah tersebut

$\mathrm{L}=\mathrm{P} \times \mathrm{L}$

$=16 \mathrm{~m} \times 10 \mathrm{~m}$

$=160 \mathrm{~m}^{2}$

Sampel penelitian ini berjumlah 33 siswa. data ini yaitu berupa hasil tes instrumen berupa soal tes tulis sebanyak 6 soal. Berdasarkan hasil Tabel 1.1 diatas menunjukan bahwa kesulitan siswa menyelesaiakan soal cerita materi bangun datar segiempat dengan presentase $93,99 \%$.

\section{Pembahasan}

Berdasarkan hasil tes urain khususnya indikator analisis kesulitan siswa menyelesaiakan soal cerita materi bangun datar segiempat pada nomor 2 ada 3 siswa yang mampu menyelesaikan soal dengan tepat dan benar, 33 siswa yang menyelesaikan soal kurang tepat dan tidak ada siswa yang sama sekali tidak dapat menyelesaikan soal. Dibawah ini adalah deskripsi jawaban siswa pada soal nomor 2 . 

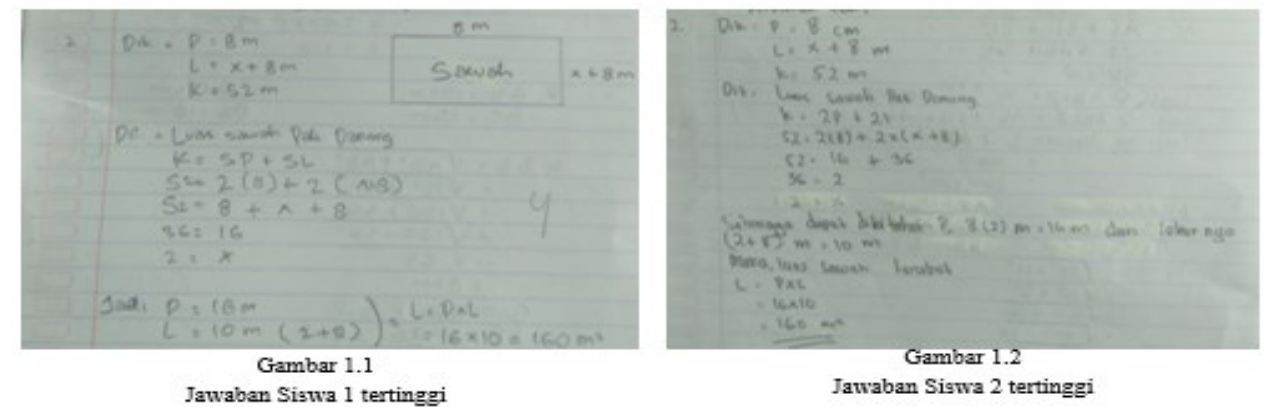

Berdasarkan Gambar 1.1 jawaban siswa 1 tertinggi yang menjawab soal dengan baik sesuai jawaban sebenarnya. Sedangkan Gambar 1.2 jawaban siswa 2 tertinggi yang mampu meyelesaikan soal dengan tepat dan benar jawaban siswa 2 lebih tepat menyelesaikan soal karena siswa dapat menjelaskan dari pada siswa mendapatkan hasil menghitung panjang dan lebar bagun segiempat dari pada jawab siswa 1 langsung menentukan panjang dan lebar bangun segiempat dari kedua jawaban siswa sudah mampu memahami soal cerita materi bangun datar segiempat dalam kehidupan sehari-hari.
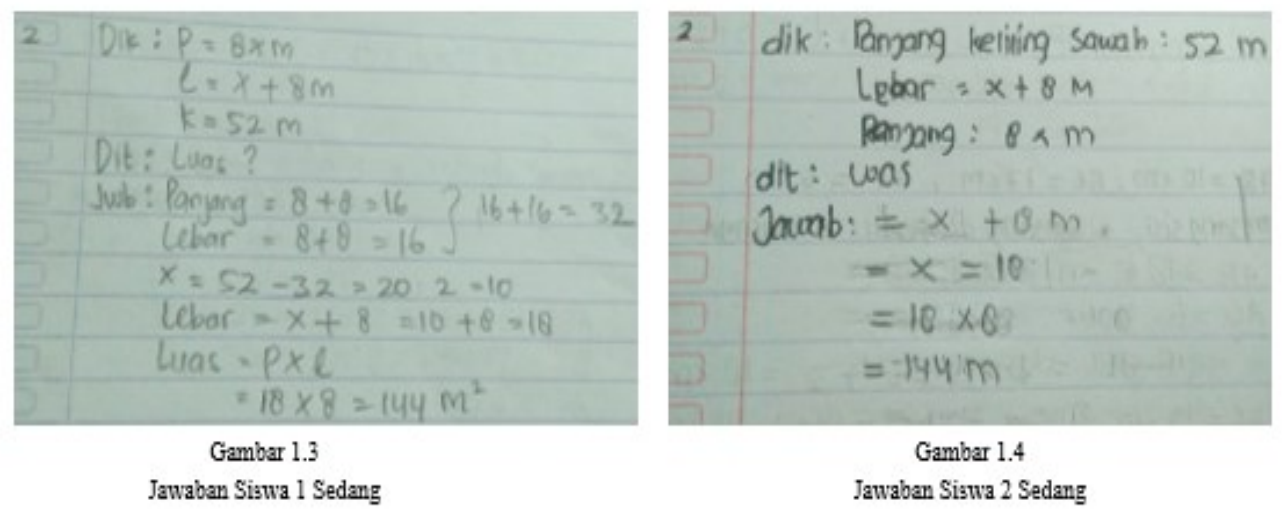

Berdasarkan Gambar 1.3 jawab siswa 1 yang jawaban sedang, siswa tersebut mengalami kesulitan kerena mengira-gira dalam menjumlahkan satuan bangun segiempat seharunya siswa menetukan rumus keliling persegi lalu menjabarkan $52=2(8 x)+2(x+8)$ baru seperti ini namun siswa langsung menjumlahkan hasil perhitungan panjang dan lebar bangun segiempat maka hal tersebut siswa tidak menyelesaikan soal sampai pada jawab akhir. Sedangkan Gambar 1.4 jawaban siswa 2 hamapir sama dengan jawan siswa pada gambar 1.3. Kesulitan yang dialami siswa 2 adalah siswa menjumlahkan langsung $\mathrm{x}+8$ seharusnya siswa menjabarkan terlebih dahulu karena siswa mengira-gira akhirnya jawaban siswa tidak sesuai dengan jawaban sebenarnya. Hal ini sejalan dengan Sari, Purwasih, \& Nurjaman (2017) bahwa pengaruh motivasi dan lingkungan teman mempengaruhi daya semangat dan keaktifan mahasiswa di kelas. Mahasiswa yang mampu menguasai konsep program linear ini mereka yang aktif bertanya dan berkelompok bersama teman yang cederung rajin belajar. 

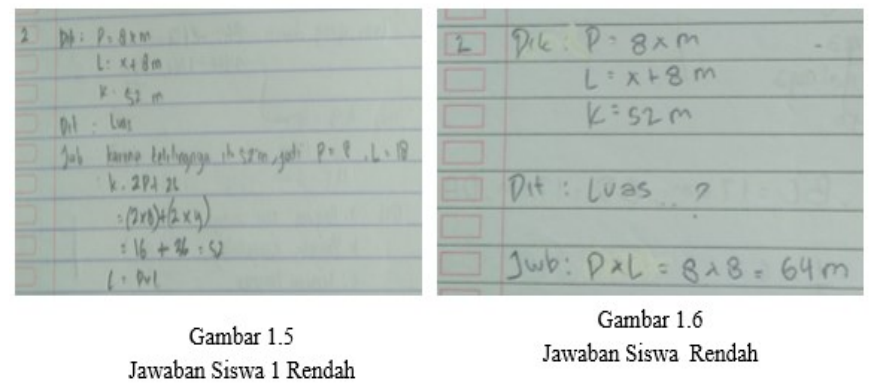

Berdasarkan Gambar 1.5 jawaban siswa 1 yang jawab rendah karena siswa kurang memahami masalah yang terdapat pada soal. Jawaban siswa tersebut menunjukan bahwa tidak memahami dengan soal cerita dengan materi bangun datar segiemapat sehingga dalam menjelaskan soal siswa tidak menyelesaikan soal sampai pada jawaban sebenarnya. Sebenarnya siswa sudah mampu menyelesaikan soal sampai pada menjumlahkan panjang dan lebar sebuah bangun segiempat, namun siswa salam mengkalikan $2 \times 9$ seharusnya siswa mengkalikan $2(8 x)$. Sedangkan Gambar 1.6 jawaban siswa 2 yang rendang siswa tersebut tidak mengerti sama sekali masalah yang ada dalam soal sehingga siswa tidak menjawab soal namun siswa hanya menjumlahkan $8+8=64$ tanpa diketahui langkah-langkah dari awal penyelesaian soal. Ketika peneliti bertanya pada salah satu siswa, apa yang membuatnya kesulitan dalam menjawab soal tersebut, siswa tersebut mengatakan karena tidak biasa dengan soal cerita. Aripin \& Purwasih (2017) bahwa Konsep atau rumus kalau diberikan secara langsung akan menjadi hafalan tetapi apabila sebuah pembelajaran yang didalamnya bertujuan untuk memahami atau menemukan konsep akan mengasah kemampuan berpikir kritis dan kreatif siswa. Kemampuan berpikir sangatlah diperlukan untuk mengadapi perkembangan ilmu pengetahuan, teknologi yang begitu cepat dan persaingan yang ketat. Biasanya mereka selalu menemukan soal yang lansung berhubungan dengan soal berhitung sehingga membuat mereka mudah menyelesaikannya dengan baik karena dengan angka-angka yang diketahui tersebut tinggal di masukan kedalam rumus, lalu selesai

\section{KESIMPULAN}

Berdasarakan hasil pelitian dan pembehasan penelitian, peneliti, disimpulkan bahwa kesulitan kemampuan pada materi bangun datar segiempat, di kelas VII F disalah satu Cimahi tergolong kurang dengan, 33 orang siswa yang mengikuti tes ada 2 oarang siswa yang dapat menyelesaikan soal dengan sangat baik, 33 orang siswa yang mengikuti tes ada 31 siswa yang menyelesaikan kuran tepat.

\section{UCAPAN TERIMA KASIH}

Peneliti sangat berterima kasih kepada pihak-pihak yang telah mendukung baik dalam penelitian ini, sehingga dapat berjalan dengan baik dan sesuai dengan harapan peneliti. Peneliti mengucapkan terima kasih kepada :

a. IKIP Siliwangi Bandung yang telah memebrikan wawasan dan pembekalan dalam penelitian

b. Kepada pihak sekolah di salah satu SMPN yang terdapat di kota Cimahi yang telah membantu dalam penelitian ini 


\section{DAFTAR PUSTAKA}

Aripin, U., \& Purwasih, R. (2017). Penerapan Pembelajaran Berbasis Alternative Solutions Worksheet Untuk Meningkatkan Kemampuan Berpikir Kreatif. AKSIOMA: Jurnal Program Studi Pendidikan Matematika, No. 6, Vol. 2, pp. 225-233.

Danaryanti, A., \& Noviani, H. (n.d.). Pengaruh Gaya Belajar Matematika Siswa kela VII Terhadap Kemampuan Komunikasi Matematis Di SMP. Edu-Mat Jurnal Pendidikan Matematika Siswa FKIP Universitas Lambung Mangkurat, 3(2): 204-.

Haji, S. (2012). No TitlePengarun Pembelajaran Kontekstual terhadap Kemampuan Komunikasi Matematika Siswa SMP Kota Bengkulu. Jurnal Exacta, Vol.X.

Hartono, S. \&. (2015). Keefektifan Cooperative Learning STAD dan GI ditinjau dari Kemampuan Berpikir Kritis dan Komunikasi Matematis. Jurnal Riset Pendidikan Matematika, Volume $2 \mathrm{~N}$.

Junaidah. (n.d.). Meningkatkan kemampuan Pemahaman,Kemampuan komunikasi,dan Disposisi Matematika Siswa melalui Pendekatan Kontekstual. Jurnal Eksperimental STIT PGMI, 1(2): 53-6.

Sari,I.P., Purwasih, R., \& Nurjaman, A. (2017). Analisis Hambatan Belajar Mahasiswa Pada Mata Kuliah Program Linear. JIPM (Jurnal Ilmiah Pendidikan Matematika), No. 6, Vol. 1, pp. $39-46$. 